\title{
Mitral leaflet dynamics in ischemic mitral regurgitation using high resolution MRI
}

\author{
Melissa M Levack*, Walter R Witschey, Jeremy R McGarvey, Norihiro Kondo, Gerald A Zsido, Joseph H Gorman, \\ James J Pilla, Robert C Gorman \\ From 15th Annual SCMR Scientific Sessions \\ Orlando, FL, USA. 2-5 February 2012
}

\section{Background}

Leaflet malcoaptation in ischemic mitral regurgitation (IMR) is thought to be caused by a combination of annular dilatation and leaflet tethering due to subvalvular ventricular remodeling. Despite this, little is known regarding leaflet dynamics in IMR. Using high temporal resolution MRI we describe, for the first time, the influence of post infarction ventricular remodeling on leaflet motion.

\section{Methods}

A porcine model of IMR was used. Using direct coronary ligation, five animals were subjected to a posterior myocardial infarction. Eight weeks post infarction animals underwent 4D time-resolved, flow sensitive MRI imaging, 3D MRI cine imaging and 2D phase contrast, high temporal resolution imaging of the mitral valve, left ventricle and aortic outflow tract. Three naïve animals underwent identical imaging protocols to serve as controls. Net mitral and aortic transvalvular flows were determined as well as left ventricular volumes and ejection fraction. Anterior to posterior mid-leaflet tip distances were measured throughout the cardiac cycle for quantification of temporal leaflet dynamics. Statistical significance was computed by ANOVA.

\section{Results}

Average net flow through the aortic valve was equal to average net flow through the mitral valve in both cohorts. Regurgitant fraction was $11.0 \pm 2.3 \%$ in the ischemic group. End diastolic volumes for the ischemic group (compared to controls) were $125.6 \pm 29.0 \mathrm{ml}$ (55.1 $\pm 2.5 \mathrm{ml}, \mathrm{P}=0.01)$ Similarly, end systolic volumes increased for the ischemic group $87.8 \pm 25.9 \mathrm{ml}(23.7 \pm$

University of Pennsylvania, Philadelphia, PA, USA
$3.0 \mathrm{ml}, \mathrm{P}=0.01)$. Ejection fraction decreased substantially from $57 \pm 5.5 \%$ at baseline to $31.2 \pm 7.7 \%(\mathrm{P}=0.002)$ with the development of IMR. Analysis of temporal

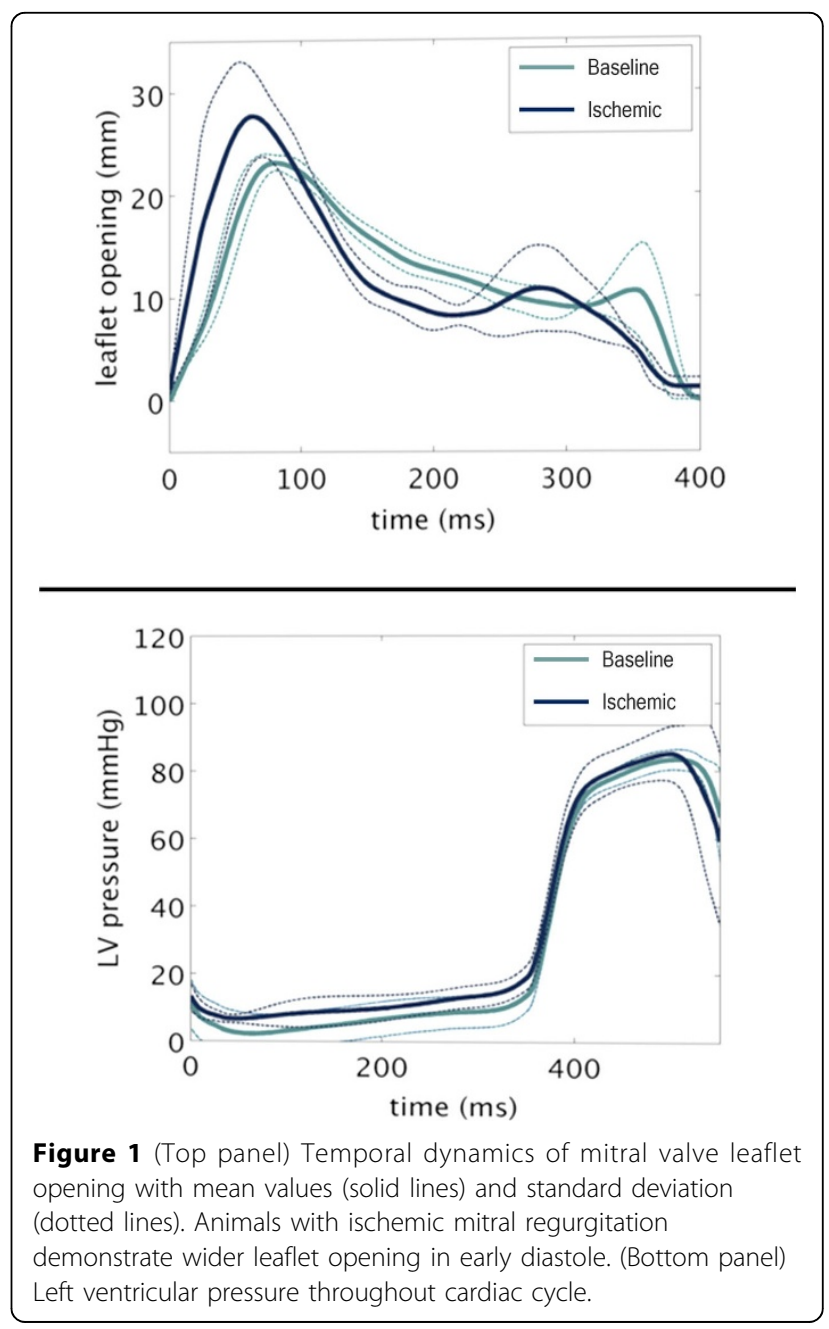

(C) 2012 Levack et al; licensee BioMed Central Ltd. This is an open access article distributed under the terms of the Creative Commons :H Wed Central Attribution License (http://creativecommons.org/licenses/by/2.0), which permits unrestricted use, distribution, and reproduction in any medium, provided the original work is properly cited. 
leaflet dynamics revealed that the early diastolic peak leaflet separation at the A2-P2 scallop was wider in the ischemic group $(23 \pm 0.1 \mathrm{~mm}$ vs $30.1 \pm 4.0 \mathrm{~mm}, \mathrm{P}<$ 0.05). Both cohorts demonstrated interval leaflet closure through mid diastole followed by a blunted enlargement of the opening area during atrial contraction. Figure 1.

\section{Conclusions}

Ventricular dilatation in IMR leads to significant increases in leaflet separation during diastole. The use of high temporal resolution MRI for assessing dynamic leaflet motion can serve as an important addition in future studies looking at the effects of various therapeutic options on valve physiology.

\section{Funding}

This work was supported by grants from the National Heart, Lung and Blood Institute of the National Institutes of Health, Bethesda, MD (HL63954, HL73021 and HL103723). R. Gorman and J. Gorman are supported by individual Established Investigator Awards from the American Heart Association, Dallas, TX.

Published: 1 February 2012

doi:10.1186/1532-429X-14-S1-W57

Cite this article as: Levack et al:: Mitral leaflet dynamics in ischemic mitral regurgitation using high resolution MRI. Journal of Cardiovascular Magnetic Resonance 2012 14(Suppl 1):W57.
Submit your next manuscript to BioMed Central and take full advantage of:

- Convenient online submission

- Thorough peer review

- No space constraints or color figure charges

- Immediate publication on acceptance

- Inclusion in PubMed, CAS, Scopus and Google Scholar

- Research which is freely available for redistribution

Submit your manuscript at www.biomedcentral.com/submit 